\title{
The outcomes of internal iliac artery preservation during endovascular or open surgery treatment for aortoiliac aneurysms
}

\author{
Os resultados da preservação da artéria ilíaca interna durante o tratamento \\ endovascular ou em cirurgia aberta para aneurismas aorto-ilíacos
}

Rafael de Athayde Soares ${ }^{1}$ (D), Marcelo Fernando Matielo', Francisco Cardoso Brochado Neto', Amanda Thurler Palomo', Rodrigo Andrade Lourenço', Caroline Tanaka', Roberto Sacilotto

\begin{abstract}
Background: Internal iliac artery (IIA) preservation continues to be a challenge during open surgery or endovascular repair of abdominal aortoiliac aneurysm (AAIA). Objectives: To determine the results in terms of survival and clinical outcomes in patients with aortoiliac aneurysms (AAIA) treated with endovascular (EV) or open surgical (OS) repair. Methods: This was a retrospective consecutive cohort study of patients with AAIA who underwent EV or OS repair. Results: Post-procedure hospitalization time and intensive care unit stay were both longer in the OS group than in the EV group ( $7.08 \pm 3.5$ days vs. $3.32 \pm 2.3$ days; $p=0.03 ; 3.35 \pm 2.2$ days vs. $1.2 \pm 0.8$ days; $p=0.02$, respectively). There were two cases of bowel ischemia (4.7\%; OS 8.3\% and EV 3.2\%; $p=0.48)$, two cases of buttock claudication ( $4.7 \%$; OS $8.3 \%$ and EV 3.2\%; $\mathrm{p}=0.48$ ), and one case of sexual dysfunction (2.3\% OS), all of them in patients with bilateral occlusion of the internal iliac artery (five patients, $11.6 \%$; $p=0.035$ ). Overall survival at 720 days was $80.6 \%$ in the EV group and $66.7 \%$ in the OS group $(p=0.58)$. Conclusions: In the present study, OS and EV repair of aortoiliac aneurysms had similar overall survival and outcomes. Preservation of at least one internal iliac artery is associated with good results and no further complications.
\end{abstract}

Keywords: endovascular surgery; aortic aneurysm; iliac aneurysm; aortoiliac open surgery.

\section{Resumo}

Contexto: A preservação de uma artéria ilíaca interna continua a ser um desafio terapêutico nos pacientes com aneurismas aorto-ilíacos submetidos tanto ao tratamento endovascular quanto a cirurgia aberta. Objetivos: Determinar os resultados da sobrevida e desfechos clínicos em pacientes com aneurismas aorto-ilíacos (AAIA) que recebem reparo endovascular (EV) ou cirúrgico aberto (CA). Métodos: Este foi um estudo de coorte consecutivo e retrospectivo de pacientes com AAIA submetidos a reparo EV ou CA. Resultados: Houve maior tempo de internação pós-procedimento e permanência na unidade de terapia intensiva no grupo CA comparado com o grupo EV (7,08 $\pm 3,5$ dias vs. 3,32 $\pm 2,3$ dias; $p=0,03 ; 3,35 \pm 2,2$ dias vs. 1,2 $\pm 0,8$ dias; $p=0,02$, respectivamente). Houve dois casos de isquemia intestinal (4,7\%; CA 8,3\% e EV 3,2\%; p = 0,48), dois casos de claudicação das nádegas (4,7\%; CA 8,3\% e EV $3,2 \% ; p=0,48)$ e um caso de disfunção sexual (2,3\% CA), todos em pacientes com oclusão bilateral da artéria ilíaca interna (All) (cinco pacientes, 11,6\%; p = 0,035). A sobrevida global aos 720 dias foi de 80,6\% no grupo EV e de 66,7\% no grupo CA ( $p=0,58)$. Conclusões: No presente estudo, o EV e o CA para aneurismas aorto-ilíacos apresentaram sobrevida e desfechos clínicos semelhantes. A preservação de pelo menos uma All está associada a bons resultados e sem complicações adicionais.

Palavras-chave: cirurgia endovascular; aneurisma aorto-ilíaco; artéria ilíaca interna; cirurgia aberta.

How to cite: Soares RA, Matielo MF, Brochado Neto FC, et al. The outcomes of internal iliac artery preservation during endovascular or open surgery treatment for aortoiliac aneurysms. J Vasc Bras. 2020;19:e20200087. https://doi. org/10.1590/1677-5449.200087 


\section{INTRODUCTION}

Internal iliac artery (IIA) preservation continues to be a challenge during open surgery or endovascular repair of abdominal aortoiliac aneurysm (AAIA). Because the IIA is primarily responsible for pelvic perfusion, its preservation is important to avoid colonic ischemia, spinal ischemia, and buttock claudication and sexual dysfunction. Iliac aneurysms are associated with abdominal aortic aneurysms (AAA) in $20 \%$ to $30 \%$ of cases. ${ }^{1}$

Over the years, several treatment options have been developed to preserve the IIA. Open surgical (OS) approaches include bypass and even endoaneurysmorrhaphy. Endovascular techniques include covered stenting with sandwich techniques and, more recently, use of iliac branch devices. ${ }^{2,3}$ Nevertheless, preservation of at least one IIA is associated with safe and acceptable results without the need to preserve both IIAs, which can increase the degree of technical difficulty during surgery and the rate of complications, especially in patients with high cardiac risk.

Therefore, the objective of this study was to determine the outcomes of survival, endoleaks, reinterventions, buttock claudication, and perioperative mortality rate (PMR) in patients with AAIA treated with endovascular or OS repair related to IIA preservation.

\section{METHODS}

Written patient informed consent was obtained for the study using a Helsinki Declaration compliant form. The study was approved by the research ethics committee. This was a retrospective, consecutive cohort study of patients with AAIA who underwent endovascular treatment or open surgical repair at the Division of Vascular and Endovascular Surgery, between January 2010 and April 2018. Patient data were collected from the vascular surgery service database and hospital records. Study was approved by Ethical Committee (number 34953614.3.0000.5463).

The study subjects were patients with AAIA who had undergone OS or endovascular repair. The decision on which type of surgical repair to use, OS or endovascular surgery, was made by the service's vascular surgeons at weekly clinical discussion meetings. Patients with suitable aortic anatomy and high cardiac risk were scheduled to undergo endovascular repair. Patients with better cardiac risk and unsuitable anatomy for endovascular repair were scheduled for OS repair. All patients were evaluated preoperatively by the same cardiologist, with surgical risk stratification performed in accordance with the Brazilian Society of Cardiology's preoperative evaluation guidelines. We defined the following three categories of cardiovascular mortality risk: low risk ( $<3 \%)$, moderate risk (3-15\%), and high risk $(>15 \%)$. Intraoperative arteriography procedures were re-evaluated to confirm that our departmental protocols had been executed accurately and to note the diameters and lengths of endoprostheses and stents, or coils. The indication for aneurysm surgery was either an AAA diameter larger than $55 \mathrm{~mm}$ or a common iliac artery diameter larger than $30 \mathrm{~mm}$.

Endovascular repair was primarily performed using an aortoiliac endoprosthesis combined with IIA coil embolization. If both IIAs were involved and it was necessary to embolize both of them, a period of at least 2 weeks was observed between procedures. The preferred technique for embolizing the IIA was with proximal coil embolization, avoiding embolizing the more distal vessels. This technique is associated with fewer ischemic complications. More recently, depending on the availability of endoprostheses, the Zenith Bifurcated Iliac Side Branch Device (ZBIS ${ }^{\circledR}$, Cook Medical) endoprosthesis was adopted in the vascular surgery department to preserve at least one IIA in conditions involving aortoiliac aneurysms. All patients were transferred to the intensive care unit (ICU) after surgery, where they remained for at least 24 hours before being transferred to a hospital unit.

The OS repairs were performed with a transperitoneal or retroperitoneal approach, depending on the vascular surgeon scheduled to treat the patient. The IIA aneurysms were preferably treated with artery ligation to exclude the IIA or, in some cases, the IIA was excluded with an endosuture in the proximal stump of the artery.

All of the patients were scheduled for follow-up at the hospital at 1, 6, and 12 months after discharge. After the first year, the patients were followed-up every 6 months and then every 12 months after the second year, at which time the following clinical criteria were evaluated: clinical examination, computed tomography scan, and Doppler ultrasonography. Technical success rates and early or late complications were reported according to the reporting standards of the Ad Hoc Committee for Standardized Reporting Practices in Vascular Surgery/ International Society for Cardiovascular Surgery. ${ }^{4,5}$

Statistical analyses were performed using SPSS 15.0 for Windows ${ }^{\circledR}$. Frequencies and descriptive statistics were analyzed. The chi-square test and Student's $t$ test were used to compare univariate analysis data. Survival curves were constructed using the KaplanMeier method to estimate limb salvage and survival rates. A p value $<0.05$ was considered statistically significant. The Mann-Whitney and Wilcoxon tests were used as non-parametric tests. Analyses were performed within 720 days of the procedure. 


\section{Surgical technique}

End-to-end anastomosis was performed with a 16:8 or 18:9 Dacron Y graft between the proximal graft and the distal abdominal aorta, whereas the distal anastomosis was performed with end-to-end anastomoses in distal external iliac arteries, followed by ligation of the internal iliac arteries or end-to-end anastomoses at the iliac bifurcation, to preserve IIA perfusion. Endovascular procedures for internal iliac arteries consisted of the use of coil embolization for IIA exclusion, or use of branched iliac stent-grafts such as the ZBIS ${ }^{\circledR}$ to preserve IIA flow.

\section{RESULTS}

A total of 43 patients were treated with OS or endovascular surgery between January 2010 and April 2018. The mean clinical follow-up period was $760 \pm 80$ days. Statistical analyses were performed at 720 days. Thirty-one of the 43 patients (72.1\%) were scheduled to undergo endovascular surgery and $12(27.9 \%)$ were treated with OS. Clinical characteristics were similar between the two groups, except for a higher prevalence of chronic kidney disease in the OS group $(p=0.04)$. The mean age of the whole cohort was 73.79 years, and most of patients were men $(90.7 \%)$. The most prevalent disease in the whole cohort was hypertension (79.1\%), followed by chronic kidney disease (27.9\%). All the data are summarized in Table 1. Of the patient cohort, $46.5 \%$ had high cardiac risk, due to severe cardiac disease, and this risk was higher in the endo group than the OS group $(p=0.03)$.

Regarding the indications for aneurysm repair, most of them were related to aneurysm diameter $(74.4 \%$; endo group $74.2 \%$ and OS group $75 \% ; \mathrm{p}=0.64$ ), and $25.6 \%$ were related to symptomatic aneurysms (endo group $25.8 \%$, OS group 25\%; $\mathrm{p}=0.64$ ). Most of the symptomatic indications for repair were related to aneurysm expansion (72.7\%); there were two cases of aneurysm rupture (one case in each group), and one case of blue toe syndrome (endo group). With regard to types of aneurysm, most of the patients had aortoiliac aneurysms (79.1\%), followed by common iliac artery (9.3\%), common and IIA (7\%), and IIA $(2.3 \%)$. These data are summarized in Table 2.

In the endo group, most of the patients had endovascular repair of the aneurysm with an endoprosthesis with concomitant IIA embolization with coils (27 patients; 84.4\%). Five patients received a ZBIS $®$ device (Cook Medical). These patients were evaluated during followup and had no complications, with an IIA patency rate of $100 \%$ at 720 days, and no cases of endoleaks. The most used types of prostheses were Endurant Medtronic (15 cases; 48.4\%), Zenith Cook (10 cases, $32.2 \%$ ), and Gore Excluder (6 cases, 19.4\%).

In the OS group, most of the patients underwent exclusion of the IIA through vessel ligation (10 patients). The other two patients had end-to-end anastomoses at the iliac bifurcation. Regarding patency of the IIA, before surgery, $95.3 \%$ of the patients had bilateral patency of the IIA; after surgery, $86 \%$ had at least one patent IIA. The mean diameters of the aortoiliac system were as follows: length of aortic neck $32.52 \mathrm{~mm}$, diameter of aortic aneurysm $56.66 \mathrm{~mm}$, right common iliac aneurysm $36 \mathrm{~mm}$, left common iliac aneurysm $27.03 \mathrm{~mm}$, right external iliac diameter $11.40 \mathrm{~mm}$, left external iliac diameter $10.91 \mathrm{~mm}$, right internal iliac diameter $16.77 \mathrm{~mm}$, and left internal iliac diameter $14.50 \mathrm{~mm}$ (Table 3).

Regarding complications, there were two cases of bowel ischemia (4.7\%; endo group 3.2\% and OS group $8.3 \% ; \mathrm{p}=0.48)$, two cases of buttock claudication (4.6\%; endo group 3.2\% and OS group $8.3 \% ; p=0.48)$, and one case of sexual dysfunction ( $2.3 \%$, in OS group). All of the patients with these complications had bilateral occlusion of the IIA (five cases, $11.6 \% ; \mathrm{p}=0.035)$. The perioperative mortality rate was $11.6 \%$ (five cases overall; four cases in the endo group and one case in the OS group, $\mathrm{p}=0.39$ ).

Table 1. Clinical characteristics of patients.

\begin{tabular}{|c|c|c|c|c|}
\hline \multirow{2}{*}{ Variable } & \multirow{2}{*}{ Total $(n=43)$} & \multirow{2}{*}{$\begin{array}{c}\text { Endo group } \\
(n=31,72.7 \%)\end{array}$} & \multirow{2}{*}{$\begin{array}{c}\text { Open surgery group } \\
(n=12,27.9 \%)\end{array}$} & \multirow{2}{*}{ p-value } \\
\hline & & & & \\
\hline Age, years & $73.79 \pm 10.84$ & $72.85 \pm 8.3$ & $73.48 \pm 7.2$ & 0.73 \\
\hline Males & $39(90.7 \%)$ & $27(87.1 \%)$ & $12(100 \%)$ & 0.25 \\
\hline Hypertension & $34(79.1 \%)$ & $23(74.2 \%)$ & $11(91.7 \%)$ & 0.16 \\
\hline Diabetes & $6(14 \%)$ & $5(16.1 \%)$ & $1(8.3 \%)$ & 0.33 \\
\hline Ischemic heart disease & $8(18.6 \%)$ & $6(19.4 \%)$ & $2(16.7 \%)$ & 0.27 \\
\hline Chronic kidney disease & $12(27.9 \%)$ & $6(19.4 \%)$ & $6(50 \%)$ & 0.04 \\
\hline Chronic pulmonary disease & $11(25.6 \%)$ & $9(29 \%)$ & $2(16.7 \%)$ & 0.23 \\
\hline Tobacco use & $11(25.6 \%)$ & $8(25.8 \%)$ & $3(25 \%)$ & 0.30 \\
\hline Claudication history & $4(9.3 \%)$ & $3(9.7 \%)$ & $1(8.3 \%)$ & 0.43 \\
\hline Increased cardiac risk & $20(46.5 \%)$ & $17(54.8 \%)$ & $3(25 \%)$ & 0.03 \\
\hline
\end{tabular}


Table 2. Procedure data.

\begin{tabular}{|c|c|c|c|c|}
\hline \multirow{2}{*}{ Variable } & \multirow{2}{*}{ Total $(n=43)$} & Endo group & Open surgery group & \multirow{2}{*}{ p-value } \\
\hline & & $(n=31,72.7 \%)$ & $(n=12,27.9 \%)$ & \\
\hline \multicolumn{5}{|l|}{ Indication for surgery } \\
\hline Aneurysm diameter & $32(74.4 \%)$ & $23(74.2)$ & $9(75 \%)$ & 0.64 \\
\hline Symptomatic aneurysm & $11(25.6 \%)$ & $8(25.8 \%)$ & $3(25 \%)$ & 0.64 \\
\hline Expansion & $8(18.6 \%)$ & $6(19.4 \%)$ & $2(16.7 \%)$ & 0.54 \\
\hline Aneurysm rupture & $2(4.7 \%)$ & $1(3.2 \%)$ & $1(8.3 \%)$ & 0.54 \\
\hline Blue toe syndrome & $1(2.3 \%)$ & $1(3.2 \%)$ & $0(0 \%)$ & 0.54 \\
\hline \multicolumn{5}{|l|}{ Types of aneurysms } \\
\hline Aortoiliac & $34(79.1 \%)$ & $24(77.4 \%)$ & $10(83.3 \%)$ & 0.24 \\
\hline Common iliac artery & $4(9.3 \%)$ & $4(12.9 \%)$ & $0(0 \%)$ & 0.02 \\
\hline Aortic aneurysm & $1(2.3 \%)$ & $1(3.2 \%)$ & $0(0 \%)$ & 0.08 \\
\hline Internal iliac aneurysm & $1(2.3 \%)$ & $1(3.2 \%)$ & $0(0 \%)$ & 0.08 \\
\hline Common iliac + internal iliac aneurysm & $3(7 \%)$ & $1(3.2 \%)$ & $2(16.7 \%)$ & 0.08 \\
\hline
\end{tabular}

Table 3. Technical data on procedures.

\begin{tabular}{|c|c|c|c|c|}
\hline \multirow[t]{2}{*}{ Variable } & \multirow[t]{2}{*}{ Total $(n=43)$} & Endo group & $\begin{array}{c}\text { Open surgery } \\
\text { group }\end{array}$ & \multirow[t]{2}{*}{$\mathrm{p}$-value } \\
\hline & & $(n=31,72.7 \%)$ & $(n=12,27.9 \%)$ & \\
\hline \multicolumn{5}{|l|}{ Endovascular procedures } \\
\hline IIA coil embolization & $27(62.7)$ & $27(84.4)$ & 0 & \\
\hline $\mathrm{ZBIS}^{\oplus}$ & $5(11.6)$ & $5(16.1 \%)$ & 0 & \\
\hline \multicolumn{5}{|l|}{ Open surgery } \\
\hline End-to-end anastomoses at iliac bifurcation & $2(4.65)$ & 0 & $2(16.6)$ & \\
\hline Exclusion of the IIA & $10(23.2)$ & 0 & $10(83.3)$ & \\
\hline \multicolumn{5}{|l|}{ Diameters (mm) } \\
\hline Aortic aneurysm & $56.66 \pm 25.6$ & $58.70 \pm 26.8$ & $59.94 \pm 24.5$ & 0.24 \\
\hline Right Common iliac aneurysm & $36 \pm 10.1$ & $38 \pm 11.2$ & $34 \pm 12.5$ & 0.36 \\
\hline Left common iliac aneurysm & $27.03 \pm 11.3$ & $26.09 \pm 12.3$ & $28.02 \pm 14.3$ & 0.45 \\
\hline Right external iliac & $11.40 \pm 0.8$ & $10.80 \pm 0.9$ & $12.45 \pm 0.7$ & 0.90 \\
\hline Left external iliac & $10.91 \pm 0.7$ & $10.83 \pm 0.6$ & $11.84 \pm 0.8$ & 0.87 \\
\hline Right external iliac & $11.40 \pm 0.9$ & $10.87 \pm 0.8$ & $11.80 \pm 0.7$ & 0.97 \\
\hline Right internal iliac & $16.77 \pm 10.2$ & $16.32 \pm 14.3$ & $16.28 \pm 15.2$ & 0.88 \\
\hline Left internal iliac & $14.50 \pm 15.6$ & $14.28 \pm 14.3$ & $14.78 \pm 15.6$ & 0.76 \\
\hline
\end{tabular}

The $13 \%$ perioperative mortality in the endo group comprised 1 death related to bowel ischemia and 3 deaths related to cardiac ischemia complications. There were seven cases of immediate endoleak in the endo group (22.58\%): two cases of endoleak type IA, four cases of endoleak type II, and one case of endoleak type IB. There were nine cases of late endoleaks: seven cases of endoleak type II and two cases of IB endoleak. The rate of freedom from reintervention was $73.3 \%$ in the endo group. Regarding the reinterventions, there were six cases of coil embolization in the IIA combined with glue embolization with Glubran ${ }^{\circledR}$, and three cases of extension of the limb prosthesis to the external iliac artery combined with coil embolization of the IIA. In the OS group, there was one case of acute bowel ischemia due to internal iliac ligation during surgery, which caused the patient's death; two cases of acute kidney dysfunction; and one case of bronchopneumonia. There was a longer post-procedure hospital stay in the OS group compared with the endovascular surgery group ( $7.08 \pm 3.5$ days vs. $3.32 \pm 2.3$ days; $p=0.03)$. Furthermore, the ICU stay was also longer in the OS group ( $3.35 \pm 2.2$ days vs. $1.2 \pm 0.8$ days; $p=0.02)$.

We performed univariate and multivariate Cox regression analyses to identify factors related to survival rate (Table 4). The Cox regression analysis for survival rates showed that elevated cardiac risk was related to poor survival rates $(\mathrm{p}=0.001$; hazard ratio $[\mathrm{HR}]=1.40$ ) in both univariate and multivariate analysis. 
Table 4. Univariate and multivariate Cox regression analysis to identify factors related to survival rate.

\begin{tabular}{|c|c|c|c|c|c|c|c|c|}
\hline \multirow{2}{*}{ Variable } & \multicolumn{4}{|c|}{ Univariate analysis } & \multicolumn{4}{|c|}{ Multivariate analysis } \\
\hline & B & OR & $95 \% \mathrm{Cl}$ & p-value & B & OR & $95 \% \mathrm{Cl}$ & p-value \\
\hline Cardiac disease & 0.517 & 6.890 & $0.128-2.767$ & 0.068 & .542 & 7.890 & $0.226-10.567$ & 0.880 \\
\hline Chronic kidney disease & 0.299 & 0.830 & $0.262-2.501$ & 0.547 & 1.286 & 1.412 & $0.820-4.294$ & 0.642 \\
\hline Tobacco use & 0.984 & 0.869 & $0.222-1.511$ & 0.864 & 0.885 & 0.906 & $0.411-14.234$ & 0.831 \\
\hline Diabetes & 0.686 & 0.913 & $0.540-1.543$ & 0.172 & 0.711 & 0.915 & $0.358-11.240$ & 0.439 \\
\hline Indication for surgery & 13.953 & 0.731 & $0.331-1.429$ & 0.649 & 1.032 & 0.514 & $0.231-5.433$ & 0.552 \\
\hline Bifurcated iliac endoprosthesis & 0.453 & 0.806 & $0.231-0.811$ & 0.615 & 0.249 & 0.262 & $0.612-1.811$ & 0.618 \\
\hline Increased cardiac risk & 12.564 & 1.499 & $1.456-2.365$ & 0.001 & 11.595 & 1.500 & $1.234-4.321$ & 0.002 \\
\hline
\end{tabular}

$\mathrm{B}=$ coefficient; $\mathrm{OR}$ = odds ratio; $\mathrm{Cl}=$ confidence interval.

Table 5. Univariate and multivariate Cox regression analyses to identify factors related to reintervention.

\begin{tabular}{|c|c|c|c|c|c|c|c|c|}
\hline \multirow{2}{*}{ Variable } & \multicolumn{4}{|c|}{ Univariate analysis } & \multicolumn{4}{|c|}{ Multivariate analysis } \\
\hline & B & OR & $95 \% \mathrm{Cl}$ & $\mathbf{P}$ & B & OR & $95 \% \mathrm{Cl}$ & $\mathbf{P}$ \\
\hline Cardiac disease & .615 & 6.000 & $.028-9.790$ & .057 & .597 & 7.000 & $0.496-8.954$ & .780 \\
\hline Chronic kidney disease & .897 & 7.637 & $0.163-4.401$ & .437 & 0.386 & 2.315 & $1.720-3.394$ & .432 \\
\hline Tobacco use & .984 & 0.869 & $0.222-1.511$ & .864 & 0.885 & 0.906 & $0.411-14.234$ & .831 \\
\hline Diabetes & .686 & 0.913 & $0.540-1.543$ & .172 & 0.711 & 0.915 & $0.358-11.240$ & .439 \\
\hline Indication for surgery & 10.953 & 0.731 & $0.431-2.429$ & .529 & 2.132 & 0.347 & $0.821-4.363$ & .890 \\
\hline Bifurcated iliac endoprosthesis & 1.453 & 0.806 & $1.831-6.911$ & .415 & 0.589 & 0.876 & $0.712-2.815$ & .578 \\
\hline Immediate endoleak & 8.554 & 1.359 & $0.356-1.265$ & .987 & 2.395 & 2.308 & $2.564-4.121$ & .876 \\
\hline Late endoleak & 5.564 & 3.700 & $1.321-4.875$ & .035 & 4.765 & 3.400 & $1.542-4.589$ & .035 \\
\hline Number of patent internal iliac arteries & 0.709 & 1.954 & $0.062-3.888$ & .501 & 0.709 & 1.054 & $0.098-2.768$ & .890 \\
\hline
\end{tabular}

$\mathrm{B}=$ coefficient; $\mathrm{OR}=$ odds ratio; $\mathrm{Cl}=$ confidence interval.

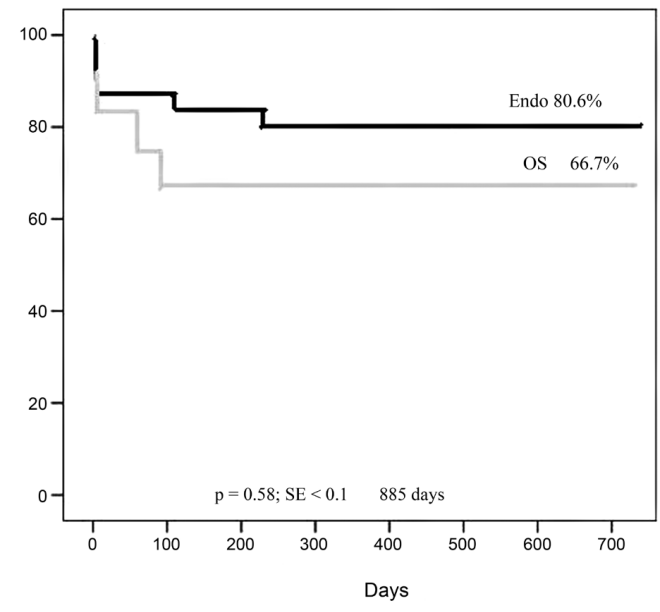

Figure 1. Overall survival at 720 days by the Kaplan-Meier method was $80.6 \%$ in the endo group and $66.7 \%$ in the open surgery (OS) group, but there was no statistically significant difference between the groups $(p=0.58)$.

The univariate and multivariate Cox regression analysis related to reintervention rates showed that late endoleak was the only factor related to reintervention $(\mathrm{HR}=3.7 ; \mathrm{p}=0.035)($ Table 5$)$.

Overall survival rates at 720 days according to the Kaplan-Meier method were $80.6 \%$ in the endo group and $66.7 \%$ in the OS group, but with no statistically significant difference between the groups $(p=0.58)$ (Figure 1).

\section{DISCUSSION}

According to American Society for Vascular Surgery documents, preservation of at least one IIA is strongly recommended during repair of aortoiliac aneurysms. Furthermore, it is also recommended that bilateral IIA occlusion be conducted in two stages, separated by at least 1 to 2 weeks, if required for endovascular correction of aortic aneurysm. ${ }^{6}$ Our vascular department's practice is to strictly adhere to this recommendation during correction of abdominal aortoiliac aneurysms. Regarding patency of the IIA, $95.3 \%$ of the patients had bilateral IIA patency before surgery. After surgery, $86 \%$ had at least one patent IIA. All patients in this cohort who had bilateral IIA occlusion had complications afterwards: two patients with bowel ischemia $(4.7 \%$; endo group $3.2 \%$ and OS group $8.3 \% ; \mathrm{p}=0.48$ ), two patients with buttock claudication (4.7\%; endo group 3.2\% and OS group $8.3 \% ; \mathrm{p}=0.48$ ), and one patient with sexual dysfunction ( $2.3 \%$, OS group). This therefore underscores the need to preserve at least one IIA to avoid ischemic complications.

Bosanquet et al. ${ }^{7}$ published a systematic review in which 2671 patients and 2748 IIAs were analyzed. 
Buttock claudication occurred in $27.9 \%$ of patients, although in $48.0 \%$ it resolved after 21.8 months. Buttock claudication rates were $32.6 \%$ with coils, $23.8 \%$ with plugs, and $12.9 \%$ with coverage alone, and fewer with unilateral (vs. bilateral) IIA treatment (OR 0.57, 95\% CI 0.36-0.91). There were two cases of buttock claudication (4.65\%) in the present cohort. Buttock claudication was related to bilateral IIA exclusion, while patients who had unilateral IIA exclusion did not have buttock claudication. IIA embolization was performed using coils in $100 \%$ of cases in the present cohort. These findings are similar to those that Mansour et $a .^{8}$ reported in a retrospective study in which buttock claudication and sexual dysfunction rates were significantly higher in the group that underwent bilateral IIA occlusion than in the group with at least one IIA preserved $(\mathrm{p}<0.05)$. Their conclusion was that at least one IIA should be salvaged in cases of bilateral involvement.

Another important embolization technique for avoiding ischemic complications that is employed at our vascular department is proximal IIA embolization, avoiding embolizing the more distal vessels, such as the gluteal branches. Maleux et al. ${ }^{9}$ have concluded that ipsilateral coil or microcoil embolization of the proximal IIA before stent-graft extension in patients previously treated by an aortic stent-graft seems to be safe and feasible, with favorable outcomes after a mean follow-up period of 39 months. The incidence of buttock claudication was $38 \%$ of patients and there were no type II endoleaks through the coil-embolized internal iliac arteries. According to Bannazadeh et al., ${ }^{10}$ in a retrospective review of all patients who underwent elective endovascular aneurysm repair (EVAR), there were no significant differences in reintervention rates between iliac limb extension into the external iliac artery with IIA coil embolization, flared iliac limb $20 \mathrm{~mm}$ or greater in diameter to the iliac bifurcation, or iliac limb $20 \mathrm{~mm}$ or less ending proximal to the concomitant common iliac artery aneurysm $(4.5 \% \mathrm{vs}$. $4.8 \%$ vs. $6.2 \% ; \mathrm{P}=0.802$ ) over a mean 59.8 months of follow-up.

In the present study, five patients were treated using a ZBIS ${ }^{\circledR}$ device (ZBIS ${ }^{\circledR}$, Cook Medical). These patients were evaluated and the procedure was associated with high technical success rates and no cases of IIA occlusion during follow-up or immediate or late endoleaks. This is comparable to what Delay et al. ${ }^{11}$ found with relation to short and mid-term results for the ZBIS ${ }^{\circledR}$ device. They found that primary patency of the internal iliac side branch was $84 \%$ at 1 year and $76 \%$ at 2 years (five perioperative IIA occlusions and one late occlusion). Freedom from reintervention was $89 \%$ at 1 and 2 years. In the present cohort, IIA branch patency was achieved in $100 \%$ of cases, but few cases were treated and follow-up was only 2 years. Farivar et al. ${ }^{12}$ found freedom from type I or III endoleaks at 3, 5, and 10 years in $99 \%$ of the cases in which a bifurcated iliac endoprosthesis was used to treat aortoiliac aneurysms and reported primary patency at 3,5 , and 10 years of $94 \%, 94 \%$, and $77 \%$, respectively.

In a very recent publication, Mendes et al. ${ }^{13}$ evaluated the perioperative outcomes of patients with iliac aneurysms treated by OS versus endovascular repair with iliac branch endoprostheses. They found that perioperative mortality occurred in one patient in the OS group (4\%), with no mortality in the iliac branch endoprosthesis group $(\mathrm{P}=0.37)$. Furthermore, the total length of hospital and ICU stay was longer for the OS group compared with the iliac branch endoprosthesis group (total stay $7.5 \pm 3.4$ vs. $1.7 \pm$ 1.4 days for IBE, $\mathrm{P}<0.0001$, and ICU $3.3 \pm 2.1$ vs. $0.1 \pm 0.4$ days, $\mathrm{P}<0.0001)$. These data are similar to what we found in the present cohort, in which lengths of both hospital and ICU stays were longer in the OS group. This may be because of the laparotomy and more invasive procedure performed in OS than in endo repair. Although not statistically significant, in this study there were more cases of perioperative deaths in the endovascular group than in the OS group and this result was because of the higher cardiac risk in the endo group compared with the OS group, with statistical significance.

Kobe et al. ${ }^{14}$ found 17 endoleaks ( 6 type I, 10 type II, and 1 type III) in a group of 72 patients with 85 IIAAs treated with endovascular repair. The overall reintervention rate was $16.7 \%$. The primary patency rate was $98.6 \%$. In the present study, we found primary IIA patency of $86 \%$ at 720 days, and a reintervention rate of $26.4 \%$ at 720 days. The main factor related to reintervention in the present cohort was late endoleak, and the endovascular technique performed did not influence the rates of endoleak or reintervention. The overall survival at 720 days was similar in the OS and endo groups in the present cohort and is similar to rates found by the United Kingdom EVAR Trial Investigators, where the endovascular repair group had an early benefit with respect to aneurysm-related mortality, but the benefit was lost by the end of the study, at least partially because of fatal endograft ruptures (adjusted HR, 0.92; 95\% confidence interval [CI], 0.57-1.49; $\mathrm{P}=0.73){ }^{15}$

This study has some limitations, in that it is a single-center retrospective study with a cohort that is not very large, especially in terms of the patients who underwent repair with iliac branch endoprostheses and the conclusions are based on a small number 
of operations from a retrospective study. Larger, prospective studies should be conducted.

\section{CONCLUSION}

In the present study, the OS and endovascular procedures for aortoiliac aneurysms had similar overall survival rates, buttock claudication rates, and perioperative mortality rates. Preservation of at least one IIA is associated with good results and no further complications. Reinterventions were performed exclusively in the endo group, due to late endoleaks. However, the endo group had shorter hospital and ICU stays compared with the OS group.

\section{REFERENCES}

1. Ziegler P, Avgerinos ED, Umscheid T, Perdikides T, Erz K, Stelter WJ. Branched iliac bifurcation: 6 years experience with endovascular preservation of internal iliac artery flow. J Vasc Surg. 2007;46(2):20410. http://dx.doi.org/10.1016/j.jvs.2007.04.015. PMid:17600664.

2. Rana MA, Kalra M, Oderich GS, et al. Outcomes of open and endovascular repair for ruptured and nonruptured internal iliac artery aneurysms. J Vasc Surg. 2014;59(3):634-44. http://dx.doi. org/10.1016/j.jvs.2013.09.060. PMid:24571938.

3. Machado RM, Rego DNC, Oliveira PNFP, Almeida RMGF. Endovascular treatment of internal iliac artery aneurysms: single center experience. Rev Bras Cir Cardiovasc. 2016;31(2):127-31. http://dx.doi.org/10.5935/1678-9741.20160023. PMid:27556311.

4. Ahn SS, Rutherford RB, Johnston KW, et al. Reporting standards for infrarenal endovascular abdominal aortic aneurysm repair. J Vasc Surg. 1997;25(2):405-10. http://dx.doi.org/10.1016/S07415214(97)70363-X. PMid:9052576.

5. Chaikof EL, Blankensteijn JD, Harris PL, et al. Reporting standards for endovascular aortic aneurysm repair. J Vasc Surg. 2002;35(5):104860. http://dx.doi.org/10.1067/mva.2002.123763. PMid:12021727.

6. Chaikof EL, Dalman RL, Eskandari MK, et al. The Society for Vascular Surgery practice guidelines on the care of patients with an abdominal aortic aneurysm. J Vasc Surg. 2018;67(1):2-77.E2. http://dx.doi.org/10.1016/j.jvs.2017.10.044. PMid:29268916.

7. Bosanquet $D C$, Wilcox $C$, Whitehurst $L$, et al. systematic review and meta-analysis of the effect of internal iliac artery exclusion for patients undergoing EVAR. Eur J Vasc Endovasc Surg. 2017;53(4):53448. http://dx.doi.org/10.1016/j.ejvs.2017.01.009. PMid:28242154.

8. Mansour W, Capoccia L, Sirignano P, et al. Clinical and functional impact of hypogastric artery exclusion during EVAR. Vasc Endovascular Surg. 2016;50(7):484-90. http://dx.doi.org/10.1177/1538574416665968. PMid:27651428.

9. Maleux G, Willems E, Vaninbroukx J, Nevelsteen A, Heye S. Outcome of proximal internal iliac artery coil embolization prior to stent-graft extension in patients previously treated by endovascular aortic repair. J Vasc Interv Radiol. 2010;21(7):990-4. PMid:20537911.

10. Bannazadeh $M$, Jenkins $C$, Forsyth $A$, et al. Outcomes for concomitant common iliac artery aneurysms after endovascular abdominal aortic aneurysm repair. J Vasc Surg. 2017;66(5):1390-7. PMid:28697942.
11. Delay C, Deglise S, Lejay A, et al. Zenith bifurcated iliac side branch device: mid-term results and assessment of risk factors for intraoperative thrombosis. Ann Vasc Surg. 2017;41:141-50. PMid:28238918.

12. Farivar BS, Abbasi MN, Dias AP, et al. Durability of iliac artery preservation associated with endovascular repair of infrarenal aortoiliac aneurysms. J Vasc Surg. 2017;66(4):1028-1036.e18. http://dx.doi.org/10.1016/j.jvs.2017.02.042. PMid:28502545.

13. Mendes BC, Oderich CS, Sandri GA, et al. Comparison of Perioperative Outcomes of Patients with lliac Aneurysms Treated by Open Surgery or Endovascular Repair with lliac Branch Endoprosthesis. Ann Vasc Surg. 2019;60:76-84.e1. http://dx.doi.org/10.1016/j. avsg.2019.05.003. PMid:31220590.

14. Kobe A, Andreotti C, Puippe G, et al. Primary endovascular elective repair and repair of ruptured isolated iliac artery aneurysms is durable-results of 72 consecutive patients. J Vasc Interv Radiol. 2018;29(12):1725-32. http://dx.doi.org/10.1016/j.jvir.2018.07.019. PMid:30396844.

15. Greenhalgh RM, Brown LC, Powell JT, Thompson SG, Epstein D, Sculpher MJ. Endovascular versus open repair of abdominal aortic aneurysm. N Engl J Med. 2010;362(20):1863-71. http://dx.doi. org/10.1056/NEJMoa0909305. PMid:20382983.

Correspondence Rafael de Athayde Soares Hospital do Servidor Público Estadual de São Paulo, Serviço de Cirurgia Vascular e Endovascular Rua Barão de Jaceguai, 908 - Campo Belo CEP 04606-000 - São Paulo (SP), Brasil Tel.: +55 (11) 99981-3931

E-mail: rafaelsoon@hotmail.com

Author information

RAS - PhD in Ciências da Saúde, Instituto de Assistência Médica ao Servidor Público Estadual de São Paulo (IAMSPE); Full member, Sociedade Brasileira de Angiologia e Cirurgia Vascular (SBACV); Board certified, SBACV in Cirurgia Vascular, Ecografia Vascular and Cirurgia Endovascular; Primary physician, vascular surgery service, Hospital do Servidor Público Estadual de São Paulo. MFM and FCBN - PhD, Universidade de São Paulo (USP); Preceptors, Hospital do Servidor Público Estadual de São Paulo.

ATP and CT - Vascular surgeons, Hospital do Servidor Público Estadual de São Paulo.

RAL - Cirurgia Vascular resident, Hospital do Servidor Público Estadual de São Paulo.

RS - PhD, Universidade de São Paulo (USP); Vascular and endovascular surgery service director, Hospital do Servidor Público Estadual de São Paulo.

\section{Author contributions Conception and design: RAS} Analysis and interpretation: RAS, MFM, FCBN, RS Data collection: CT, ATP, RAL Writing the article: RAS

Critical revision of the article: RAS, MFM, FCBN, RS, CT, RAL, ATP Final approval of the article*: RAS, MFM, FCBN, RS, CT, RAL, ATP Statistical analysis: RAS

Overall responsibility: RAS

*All authors have read and approved of the final version of the article submitted to J Vasc Bras. 